\title{
Design of a Novel Stator and Rotor Resistances Estimator for Sensorless Induction Motor Drives
}

\author{
Ahmed A. Zaki Diab", ${ }^{1, *}$ Ayat G. Abo El-Magd², Montaser Abd El Sattar ${ }^{3}$ \\ ${ }^{1}$ Electrical Engineering Department, Faculty of Engineering, Minia University, 61111 Minia, Egypt \\ ${ }^{2}$ El-Minia High Institute of Engineering and Technology, 61111 Minia, Egypt \\ ${ }^{3}$ Department of Electrical Engineering, Faculty of Engineering, South Valley University, Qena 83523, Egypt \\ a.diab@mu.edu.eg (A.A.Z.D.); yassen_mk_2012@yahoo.com (A.G.A.E.-M) and \\ Montaser.A.Elsattar@eng.svu.edu.eg (M.A.E.-S)
}

* Corresponding: Montaser Abd El Sattar (Montaser.A.Elsattar@eng.svu.edu.eg) and Ahmed A. Zaki Diab (a.diab@mu.edu.eg) Abstract - In this paper, a novel model reference adaptive system (MRAS) is introduced for estimation the stator and rotor resistances and rotor speed. The presented MRAS is designed for simultaneous identification of the three quantities in order to save the cost of implementation and processes time. The Popov's criterion is used to design the adaptation mechanisms. The validation of the modified technique is tested through Matlab/ Simulink. The results evaluate the effectiveness of the suggested algorithm under load disturbance and parameters variation.

Keywords- Model Reference Adaptive System (MRAS), Induction Motor (IM), Speed Sensorless.

\section{Introduction}

Induction motors (IMs) are commonly used as variable speed drives in industry as a result of their advantages such as rugged construction and less maintenance [1]. Moreover, the accuracy of slip speed calculation is effect on the performance of the indirect field oriented control. The slip angle is calculated from the flux producing current component, the reference of torque, and rotor parameters of the machine under consideration [2-3]. For obtaining a precise rotor position, accurate values of rotor circuit parameters are required. Thus, to achieve a high dynamic performance, accurate values of machine parameters should be used in the controller.

The schemes of rotor flux estimation with constant parameters of induction machine model suffered from inaccuracy. This is attributed to the variation of machine parameters with temperature variations, frequency and magnetic saturation. A lot of algorithms have been presented to eliminate the effect of rotor resistance in IM drives [3]. The method presented in Refs. [4-5] was based on model reference adaptation of either flux or reactive power. Ref. [6] used the artificial injection signal for estimating the output signal variation. Ref. [7] detected the variation of rotor resistance using an adaptive feedback linearization control. Also, an Extended Kalman filter was used for estimating rotor resistance in Refs. [8-9]. From these algorithms, MRAS were the most common techniques that used for the identification processes; due to their relative simplicity and low computational effort [10-13].

In the most reported papers, the MRAS was used for rotor resistance estimation only or rotor speed only with or without stator resistance estimation. So, the aim of this paper is to save the cost of implementation and

Received: 25 July, 2020, Accepted: 30 December, 2020 processes time of speed estimators.

In this paper, a novel parallel MRAS is used to identify simultaneously the stator and rotor resistances for sensorless IM drives. The stability of the proposed scheme is derived based on Popov's criterion in order to design the adaptation mechanisms. For validation the proposed scheme at different operating conditions, the Matlab/Simulink package is used to test the control system. The simulation results prove the affectivity of the control system under load disturbance and/or parameters variation.

\section{List of Symbols}

$V_{d s}, V_{q s}, i_{d s}, i_{q s}:$ The $d$-q axis stator voltage and current components (V);

$i_{d r}, i_{q r}$ : The $d$-q axes rotor current components (A);

$i_{d s}^{s}, i_{q s}^{s}, i_{d r}^{s}, i_{q r}^{s}$ : Stationary axes stator and rotor current components (A);

$L_{m}$ : Magnetizing inductance $(\mathrm{H})$;

$L_{r}, L_{s}, L_{l s}, L_{l r}$ : Stator and rotor self-leakage and leakage inductance $(\mathrm{H})$;

$\delta$ Leakage coefficient $\left(1-\frac{L_{m}^{2}}{L_{s} L_{r}}\right)$;

$T_{l}, T_{e}$ : Load and electromagnetic torques $(\mathrm{Nm})$;

$R_{s}, R_{r}$ : Stator and rotor resistances $(\Omega)$;

$\omega_{e}, \omega_{s l}, \omega_{r}, \omega_{r}^{*}$ : Synchronous, slip, rotor speeds $(\mathrm{rad} / \mathrm{sec})$;

$T_{r}:$ Rotor time constant, $T_{r}=\frac{L_{r}}{R_{r}}$;

$J$ : Moment of inertia $\left(\mathrm{kg} \cdot \mathrm{m}^{2}\right)$;

$\lambda_{d r}^{s}, \lambda_{q r}^{S}$ : Stationary axes rotor flux components ( $\left.\mathrm{wb}\right)$;

$\hat{\lambda}_{d r}^{s}, \hat{\lambda}_{q r}^{s}$ : Stationary axes estimated rotor flux components $(\mathrm{wb})$

$\lambda_{d r}, \lambda_{q r}$ : The d-q axes rotor flux components (wb);

$p=\frac{d}{d t}:$ Differential operator; 
P: No. of poles.

\section{Induction Motor Model}

The dynamic model of IM in $d^{s}-q^{s}$ stationary reference frame can be modified as follows [14]:

$$
\begin{aligned}
& \frac{d i_{q S}^{S}}{d t}=-\left(\frac{R_{S}}{L_{s} \delta}+\frac{R_{r} L_{m}^{2}}{L_{S} L_{r}^{2} \delta}\right) i_{q S}^{s}+\frac{R_{r} L_{m}}{L_{s} L_{r}^{2} \delta} \lambda_{q r}^{S}-\frac{L_{m}}{L_{s} L_{r} \delta} \omega_{r} \lambda_{d r}^{s}+ \\
& \frac{1}{L_{S} \delta} V_{q S}^{S} \\
& \frac{d i_{d s}^{S}}{d t}=-\left(\frac{R_{S}}{L_{s} \delta}+\frac{R_{r} L_{m}^{2}}{L_{S} L_{r}^{2} \delta}\right) i_{d s}^{S}+\frac{L_{m}}{L_{s} L_{r} \delta} \omega_{r} \lambda_{q r}^{s}+\frac{R_{r} L_{m}}{L_{s} L_{r}^{2} \delta} \lambda_{d r}^{S}+ \\
& \frac{1}{L_{S} \delta} V_{d s}^{S} \\
& \frac{d \lambda_{q r}^{S}}{d t}=\frac{R_{r} L_{m}}{L_{r}} i_{q s}^{S}-\frac{R_{r}}{L_{r}} \lambda_{q r}^{S}+\omega_{r} \lambda_{d r}^{s} \\
& \frac{d \lambda_{d r}^{S}}{d t}=\frac{R_{r} L_{m}}{L_{r}} i_{d s}^{s}-\omega_{r} \lambda_{q r}^{s}-\frac{R_{r}}{L_{r}} \lambda_{d r}^{s} \\
& \frac{d \omega_{r}}{d t}=\frac{1}{J}\left(T_{e}-T_{l}\right)-\frac{f_{b}}{J} \omega_{r}
\end{aligned}
$$

\section{Vector Control of the Induction Motor}

In vector control schemes, the condition of $\lambda_{q r}=0$ is well pleased. Moreover, simplified indirect vector controller can be described for calculation the slip speed as follows:

$\omega_{s l}=\omega_{e}-\omega_{r}$

and aligning the rotor flux phasor $\lambda_{r}$ on the $\mathrm{d}$-axis as follows:

$\lambda_{d r}=\lambda_{r}$

$\lambda_{q r}=0$

Then, IM rotor model is presented as follows:

$R_{r} i_{d r}+p \lambda_{r}=0$

$R_{r} i_{q r}+\omega_{s l} \lambda_{r}=0$

$i_{q r}=-\frac{L_{m}}{L_{r}} i_{q s}$

$i_{q r}=\frac{\lambda_{r}}{L_{r}}-\frac{L_{m}}{L_{r}} i_{d s}$

$\omega_{s l}=\frac{L_{m}}{T_{r}} \frac{i_{q s}}{\lambda_{r}}$

$p \lambda_{r}=\frac{1}{T_{r}}\left(-\lambda_{r}+L_{m} i_{d s}\right)$

$T_{e}=K_{T} i_{q s} \lambda_{r}$

where: $K_{T}=\frac{3}{2} \frac{p}{2} \frac{L_{m}}{L_{r}}=$ torque constant.

Considering the command torque- and flux-producing current components, $i^{*}{ }_{q s}$ and $i^{*}{ }_{d s}$, then using them for calculation the command values of the rotor flux $\lambda^{*}{ }_{r}$ and torque $T^{*}{ }_{e}$ as follows:

$$
\begin{aligned}
i^{*}{ }_{q s} & =\frac{1}{K_{T}} \frac{T^{*}{ }_{e}}{\lambda^{*} r} \\
i^{*}{ }_{d s} & =\frac{1}{L_{m}}\left(1+T_{r} p\right) \lambda^{*}{ }_{r}
\end{aligned}
$$

The slip speed command $\omega^{*}{ }_{s l}$ is expressed as follows:

$$
\begin{gathered}
\omega^{*}{ }_{s l}=\frac{L_{m}}{T_{r}} \frac{i^{*}{ }_{q s}}{\lambda_{r}^{*}} \\
\theta_{e}^{*}=\int\left(\omega_{r}+\omega_{s l}^{*}\right) d t
\end{gathered}
$$

\section{Modified MRAS}

The IM model in the stationary $d^{s}-q^{s}$ reference frame can be expressed as follows:

Reference model (stator equation):

$p\left[\begin{array}{l}\lambda_{d r}^{s} \\ \lambda_{q r}^{s}\end{array}\right]=$
$\frac{L_{r}}{L_{m}}\left(\left[\begin{array}{c}V_{d s}^{s} \\ V_{q s}^{s}\end{array}\right]-\left[\begin{array}{cc}R_{s}+\sigma L_{s} & 0 \\ 0 & R_{s}+\sigma\left(L_{m}+L_{l s}\right)\end{array}\right]\left[\begin{array}{c}i_{d s}^{s} \\ i_{q s}^{s}\end{array}\right]\right)$

Adjustable model (rotor equation):

$$
p\left[\begin{array}{l}
\hat{\lambda}_{d r}^{s} \\
\hat{\lambda}_{q r}^{s}
\end{array}\right]=\left[\begin{array}{ll}
-\frac{\hat{R}_{r}}{L_{r}} & -\widehat{\omega}_{r} \\
\widehat{\omega}_{r} & -\frac{\hat{R}_{r}}{L_{r}}
\end{array}\right]\left[\begin{array}{l}
\hat{\lambda}_{d r}^{s} \\
\hat{\lambda}_{q r}^{s}
\end{array}\right]+\frac{L_{m}}{\frac{\hat{R}_{r}}{L_{r}}}\left[\begin{array}{c}
i_{d s}^{s} \\
i_{q s}^{s}
\end{array}\right]
$$

The modified MRAS has been shown in Fig. 1. In this figure, the rotor flux is estimated using the stator model (reference model), Eq. (20), and the rotor model, Eq. (21). The stator model as shown in Eq. (20) consists of the stator resistance. But the rotor model (adjustable model) consists of the rotor resistance and speed as shown in Eq. (21). The error between the two estimators is input to the suitable adjustable mechanism to estimate the stator resistance, $\hat{R}_{s}$, rotor resistance, $\hat{R}_{r}$ or speed $\hat{\omega}_{r}$. The estimation of the rotor resistance and rotor speed from one adjustable model is based on the fact of slow variation of the rotor resistance with temperature, and also using a different sample time for the two adaptation mechanisms. The stability and the adaptation laws for speed and stator and rotor resistances estimation have been deigned based on the Popov's criterion. Using Popov's criterion, the stability of MRAS can be analyzed as shown in Eqs (22-41). The state error equation can be written using Eqs. (20) and (21) as follows:

$$
\begin{aligned}
& p\left[\begin{array}{l}
\varepsilon_{d I} \\
\varepsilon_{q I}
\end{array}\right]=\left[\begin{array}{ll}
-\frac{R_{r}}{L_{r}} & -\omega_{r} \\
\omega_{r} & -\frac{R_{r}}{L_{r}}
\end{array}\right]\left[\begin{array}{l}
\varepsilon_{d I} \\
\varepsilon_{q I}
\end{array}\right]+\frac{1}{L_{r}}\left(R_{r}-\hat{R}_{r}\right)\left[\begin{array}{l}
\hat{\lambda}_{d r I}^{s}-L_{m} i_{d S}^{s} \\
\hat{\lambda}_{q r I}^{s}-L_{m} i_{q S}^{s}
\end{array}\right]+ \\
& \left(\omega_{r}-\widehat{\omega}_{r}\right)\left[\begin{array}{l}
\hat{\lambda}_{d r I}^{s} \\
\hat{\lambda}_{q r I}^{s}
\end{array}\right]+\frac{L_{r}}{L_{m}}\left(R_{S}-\hat{R}_{s}\right)\left[\begin{array}{l}
i_{d s}^{s} \\
i_{q S}^{s}
\end{array}\right]
\end{aligned}
$$

where;

$$
\begin{aligned}
& p\left[\begin{array}{l}
\varepsilon_{d I} \\
\varepsilon_{q I} \\
\varepsilon_{d v} \\
\varepsilon_{q v}
\end{array}\right]=\left[\begin{array}{cccc}
-\frac{R_{r}}{L_{r}} & -\omega_{r} & 0 & 0 \\
\omega_{r} & -\frac{R_{r}}{L_{r}} & 0 & 0 \\
0 & 0 & 0 & 0 \\
0 & 0 & 0 & 0
\end{array}\right]\left[\begin{array}{l}
\varepsilon_{d I} \\
\varepsilon_{q I} \\
\varepsilon_{d v} \\
\varepsilon_{q v}
\end{array}\right]-w_{1}-w_{2}-w_{2} \\
& w_{1}=\frac{1}{L_{r}}\left(R_{r}-\hat{R}_{r}\right)\left[\begin{array}{l}
\hat{\lambda}_{d r I}^{s}-L_{m} i_{d s}^{s} \\
\hat{\lambda}_{q r I}^{s}-L_{m} i_{q s}^{s}
\end{array}\right]
\end{aligned}
$$


Vol. 41, No.2. July 2022

$w_{1}=\left[\begin{array}{cccc}\frac{1}{L_{r}} \Delta R_{r} & 0 & -L_{m} & 0 \\ 0 & \frac{1}{L_{r}} \Delta R_{r} & 0 & -L_{m} \\ 0 & 0 & 0 & 0 \\ 0 & 0 & 0 & 0\end{array}\right]\left[\begin{array}{l}\hat{\lambda}_{d r I}^{s} \\ \hat{\lambda}_{q r I}^{s} \\ i_{d s}^{s} \\ i_{q s}^{s}\end{array}\right]$

$S=\int_{0}^{t_{1}}[\varepsilon]^{T}\left[W_{1}\right] d t \geq-\gamma_{1}{ }^{2}$ for allt $t_{1} \geq 0$

Substituting for $\left[W_{1}\right]$ and $[\varepsilon]^{T}$ in this inequality and using the definition of $R_{r}$, Popov's criterion for the present system becomes:

$\int_{0}^{t_{1}}\left\{\left[\varepsilon_{d I} \varepsilon_{q I}\right]\left[\left[\begin{array}{l}\hat{\lambda}_{d r I}^{s}-L_{m} i_{d s}^{s} \\ \hat{\lambda}_{q r I}^{s}-L_{m} i_{q s}^{s}\end{array}\right] \frac{1}{L_{r}}\left(\hat{R}_{r}-\left[K_{P R r}+\right.\right.\right.\right.$

$\left.\left.\left.\left.\frac{K_{I R r}}{p}\right] e_{R r}\right)\right]\right\} d t \geq-\gamma_{1}{ }^{2} \quad$ for all $t_{1} \geq 0$

A solution to this inequality can be found through the following relation:

$\int_{0}^{t_{1}} k(p \cdot f(t)) f(t) d t \geq-\frac{1}{2} k \cdot f(0)^{2}, \quad k>0$

$\hat{R}_{r}=\left[K_{P R r}+\frac{K_{I R r}}{p}\right]\left(\left[\varepsilon_{d I} \varepsilon_{q I}\right]\left[\begin{array}{l}\hat{\lambda}_{d r I}^{s}-L_{m} i_{d s}^{s} \\ \hat{\lambda}_{q r I}^{s}-L_{m} i_{q s}^{s}\end{array}\right]\right)$

$\hat{R}_{r}=\left(K_{p R_{r}}+\frac{K_{I R_{r}}}{p}\right)\left(\underline{\varepsilon}_{I}^{T} \underline{\hat{\lambda}}_{r I}^{s}-L_{m} \cdot \underline{i}_{s}^{s}\right)$

$\hat{R}_{r}=\left(K_{p R r}+\frac{K_{I R_{r}}}{p}\right)\left(\left[\varepsilon_{d I} \varepsilon_{q I}\right]\left[\begin{array}{l}\hat{\lambda}_{d r I}^{s}-L_{m} i_{d s}^{s} \\ \hat{\lambda}_{q r I}^{s}-L_{m} i_{q S}^{s}\end{array}\right]\right)$

$\hat{R}_{r}=\left[K_{P R r}+\frac{K_{I R r}}{p}\right]\left(\left(\lambda_{d r V}-\hat{\lambda}_{d r I}\right)\left(\hat{\lambda}_{d r I}^{s}-L_{m} i_{d s}^{s}\right)+\right.$

$\left.\left(\lambda_{q r V}-\hat{\lambda}_{q r I}\right)\left(\hat{\lambda}_{q r I}^{s}-L_{m} i_{q S}^{s}\right)\right)$

where; $\quad e_{R r=}\left(\lambda_{d r V}-\hat{\lambda}_{d r I}\right)\left(\hat{\lambda}_{d r I}^{s}-L_{m} i_{d s}^{s}\right)+$ $\left(\lambda_{q r V}-\hat{\lambda}_{q r I}\right)\left(\hat{\lambda}_{q r I}^{s}-L_{m} i_{q s}^{s}\right)$ and $K_{P R r}$ and $K_{I R r}$ are the parameters of PI controller of an adaptation mechanism.

$W_{2}=\left[\begin{array}{cccc}-\Delta \omega_{r}\left[\begin{array}{cc}0 & -1 \\ 1 & 0\end{array}\right] & 0 & 0 \\ 0 & 0 & 0 & 0 \\ 0 & 0 & 0 & 0\end{array}\right] \cdot\left[\begin{array}{l}\hat{\lambda}_{d r I}^{s} \\ \hat{\lambda}_{q r I}^{s} \\ i_{d s}^{s} \\ i_{q s}^{s}\end{array}\right]$

$W_{2}=\left[\begin{array}{cc}-\Delta \omega_{r} J & 0 \\ 0 & 0\end{array}\right] \cdot\left[\begin{array}{l}\hat{\lambda}_{r I}^{s} \\ \underline{i}_{s}^{s}\end{array}\right]$

Popov's criterion requires that:

$\mathrm{s}=\int_{0}^{t_{1}}[\varepsilon]^{T}\left[W_{2}\right] d t \geq-\gamma_{2}^{2}$ For all $t_{1} \geq 0$

where; $\gamma_{2}{ }^{2}$ is a positive constant, $\underline{\varepsilon}^{T}=\left[\varepsilon_{d I} \varepsilon_{q I} \varepsilon_{d V} \varepsilon_{q V}\right]=$ $\left[\underline{\varepsilon}_{I}^{T} \underline{\varepsilon}_{V}^{T}\right], \Delta \omega_{r}=\omega_{r}-\widehat{\omega}_{r}$ and $J=\left[\begin{array}{l}0-1 \\ 10\end{array}\right]$.

$S=-\int_{0}^{t_{1}} \Delta \omega_{r}\left(\underline{\varepsilon}_{J}^{T} \cdot J \cdot \underline{\hat{\lambda}}_{r I}^{s}\right) d t \geq-\gamma_{2}^{2}$

$\widehat{\omega}_{r}=\left(K_{p \omega}+\frac{K_{I \omega}}{p}\right)\left(\underline{\varepsilon}_{I}^{T} \cdot J \cdot \underline{\hat{\lambda}}_{r I}^{s}\right)$

$\widehat{\omega}_{r}=\left(K_{p \omega}+\frac{K_{I \omega}}{p}\right)\left(\underline{\hat{\lambda}}_{r I}^{s} \times \underline{\hat{\lambda}}_{r V}^{s}\right)$

$\widehat{\omega}_{r}=\left(K_{p \omega}+\frac{K_{I \omega}}{p}\right) e_{\omega}$

where; $e_{\omega}=\hat{\lambda}_{d r I}^{s} \hat{\lambda}_{q r V}^{s}-\hat{\lambda}_{q r I}^{s} \hat{\lambda}_{d r V}^{s}, K_{P \omega}$ and $K_{I \omega}$ are the parameters of PI controller of an adaptation mechanism.

$w_{3}=\left[\begin{array}{cccc}0 & 0 & 0 & 0 \\ 0 & 0 & 0 & 0 \\ 0 & 0 & \frac{-L_{r}}{L_{m}} \Delta R_{s} & 0 \\ 0 & 0 & 0 & \frac{-L_{r}}{L_{m}} \Delta R_{s}\end{array}\right]\left[\begin{array}{l}\hat{\lambda}_{d r I}^{s} \\ \hat{\lambda}_{q r I}^{s} \\ i_{d s}^{s} \\ i_{q s}^{s}\end{array}\right]$

$W_{3}=\left[\begin{array}{cc}0 & 0 \\ 0 & -\frac{L_{r}}{L_{m}} \Delta R_{s} I\end{array}\right] \cdot\left[\begin{array}{l}\hat{\lambda}_{r I}^{s} \\ \underline{i}_{s}^{s}\end{array}\right]$

$S=\int_{0}^{t_{1}}[\varepsilon]^{T}\left[W_{3}\right] d t \geq-\gamma_{3}^{2}$ for all $t_{1} \geq 0$

$\hat{R}_{s}=\left(K_{p R_{S}}+\frac{K_{I R_{s}}}{p}\right)\left(-\underline{\varepsilon}_{V}^{T} \cdot \underline{i}_{s}^{s}\right)$

$\hat{R}_{s}=\left(K_{p R_{s}}+\frac{K_{I R_{s}}}{p}\right)\left[\underline{i}_{s}^{s} \bullet\left(\underline{\hat{\lambda}}_{r V}^{s}-\underline{\hat{\lambda}}_{r I}^{s}\right)\right]$

$\hat{R}_{s}=\left(K_{p R_{S}}+\frac{K_{I R_{S}}}{p}\right) e_{R S}$

where $; e_{R s}=\hat{\imath}_{d s}^{s}\left(\hat{\lambda}_{d r V}^{s}-\hat{\lambda}_{d r I}^{s}\right)+i_{q s}^{s}\left(\hat{\lambda}_{q r V}^{s}-\hat{\lambda}_{q r I}^{s}\right)$, $I=\left[\begin{array}{l}10 \\ 01\end{array}\right], K_{P R S}$ and $K_{I R s}$ are the parameters of PI controller of an adaptation mechanism.

\section{Proposed Sensorless Vector Controlled Induction Motor Drive}

Figure 2 displays the scheme of the suggested control system for the sensorless indirect vectorcontrolled IM drive including the estimation of the rotor resistance and stator resistance. The block diagram involves the induction motor model, a hysteresis current controlled PWM, inverter, the designed vector control with a co-ordinate transformation and closed loop speed controller. Moreover, figure 2 shows the adaptive statorrotor resistance and motor speed estimator. The estimation process of the stator and rotor resistances has been designed to run in parallel at each time step in the implementation time. 
Vol. 41, No.2. July 2022

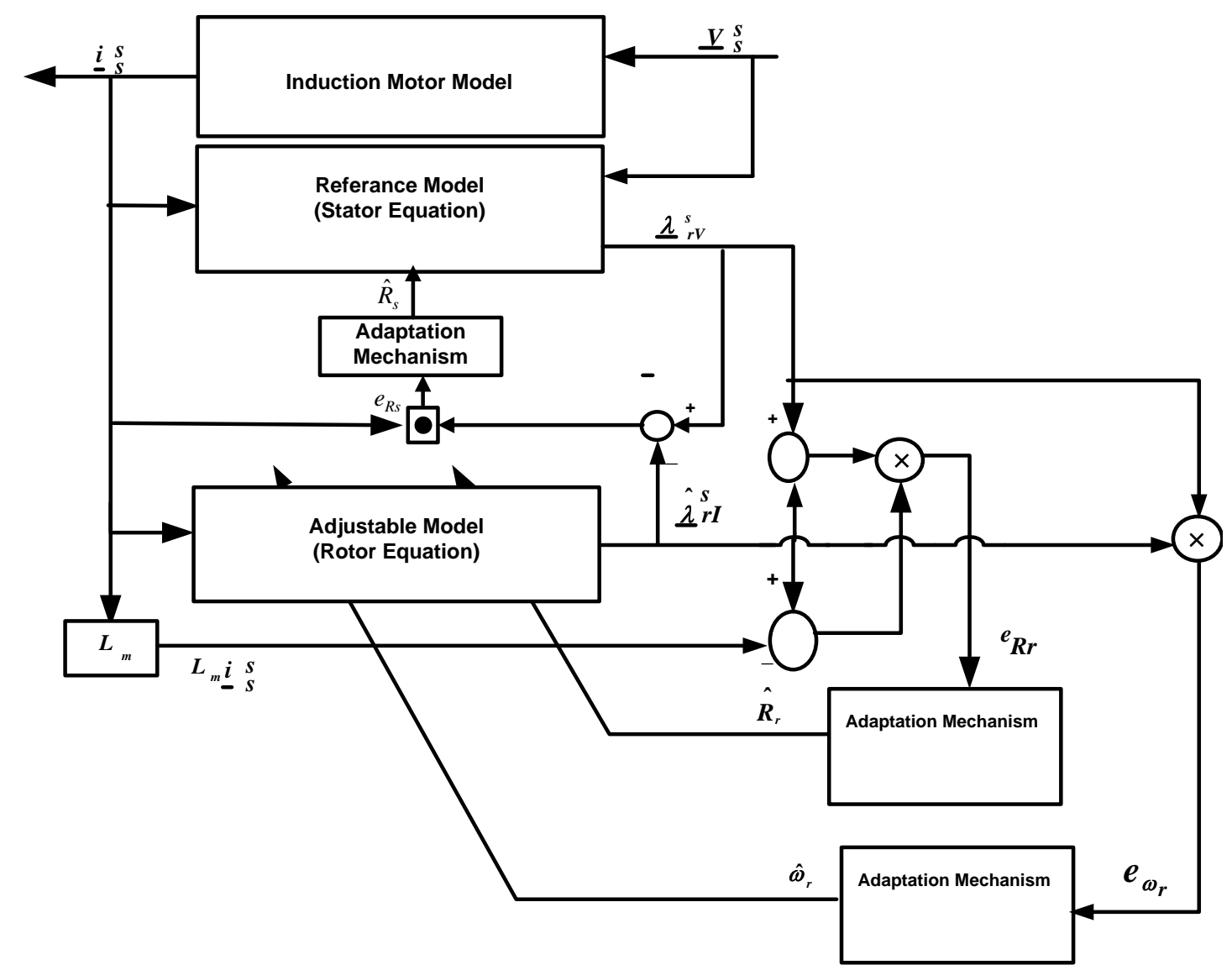

Figure 1: Structure of MRAS.

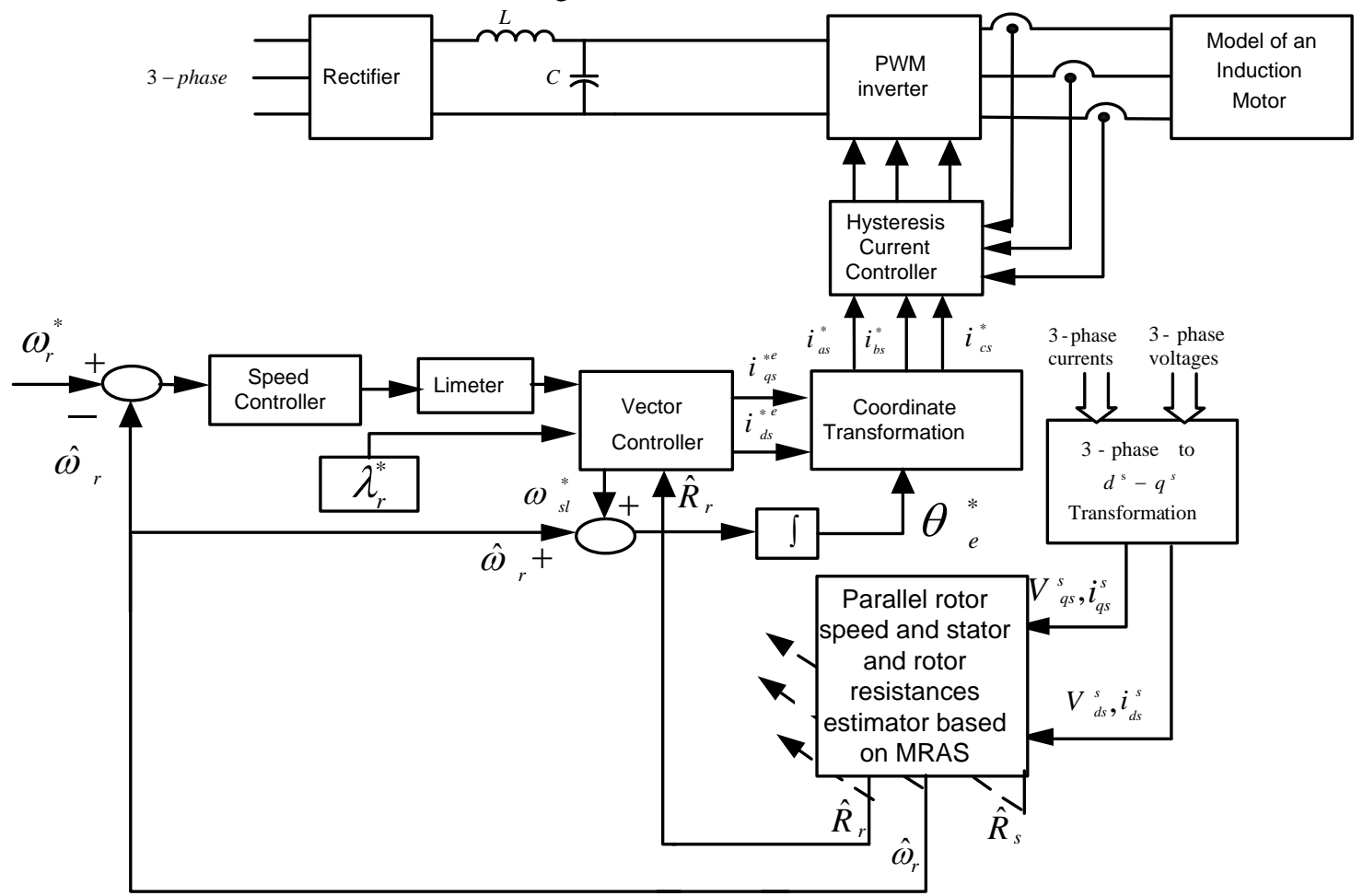

Figure 2: The block diagram of the parallel MRAS for sensorless IM drive. 


\section{Simulation Results and Discussion}

In order to validate the proposed control scheme, a 3.8 HP induction motor with four poles has been tested considering various operating conditions. The nominal parameters and specifications of induction motor have been itemized in table 1. The Matlab/ Simulink is utilized for evaluating proposed control system.

Table 1: Parameters and data specifications of the induction motor

\begin{tabular}{|c|c|c|c|}
\hline Rated power (HP) & 3.8 & Rated voltage (V) & 380 \\
\hline Rated current (A) & 8 & Rated frequency (Hz) & 50 \\
\hline $\operatorname{Rr}(\Omega)$ & 1.009 & $\operatorname{Rs}(\Omega)$ & 1.725 \\
\hline $\operatorname{Lr}(\mathrm{H})$ & 0.1473 & Ls $(\mathrm{H})$ & 0.1473 \\
\hline Lm (H) & 0.1271 & Rated rotor flux, (wb) & 0.735 \\
\hline J (kg. m2) & 0.0400 & Rated speed (rpm) & 1450 \\
\hline
\end{tabular}

The influence of variation of the rotor resistance in the IM drive is shown in Fig. 3. In this case of study, the transient performance is examined for step change of the rotor resistance when the motor is running at very low speed of $10 \mathrm{rad} / \mathrm{sec}$ at nominal load torque. Figures $3 \mathrm{a}-3 \mathrm{f}$ show the dynamic response when the rotor resistance is increased by $50 \%$ from its nominal value at $\mathrm{t}=5 \mathrm{sec}$. From Figs. 3b-3f, it is seen that, the estimated stator resistance, estimated motor speed, speed error, motor torque, and $d-q$ axes rotor flux components are

(a) actual and estimated rotor resistance (ohm)

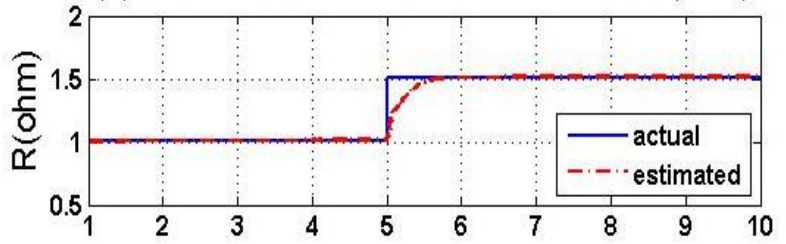

(c) actual and estimated speed ( $\mathrm{rad} / \mathrm{sec}$ )

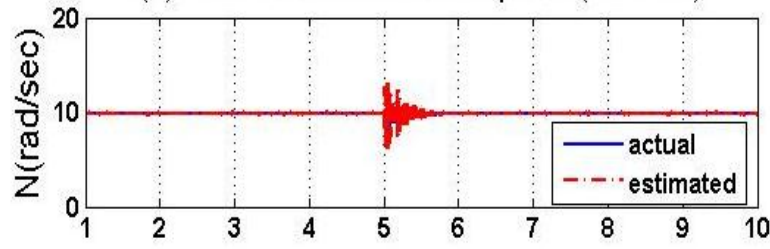

(e) electromagnetic and load torque $(\mathrm{Nm})$

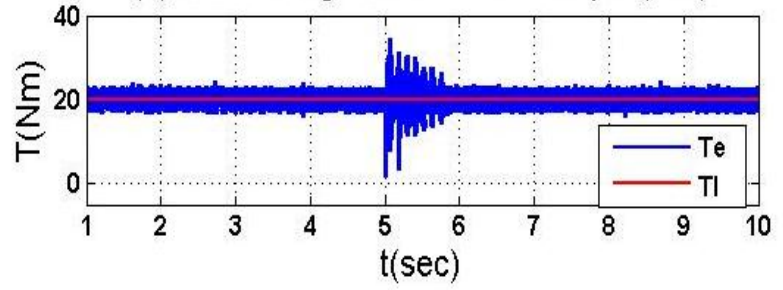

equal their command values during the rotor resistance variation.

Figure 4 shows the performance of IM drive at rated speed of $150 \mathrm{rad} / \mathrm{sec}$, rated load and $50 \%$ increment of rotor resistance. The estimated rotor and stator resistances, estimated speed, speed error, motor torque, and $d-q$ axes rotor flux components are all shown in Figs. 4a-4f. The figure shows a large spike for a very short time in estimated torque, the reasons of this large spike may be because the step variation in the rotor resistance at high speed reference speed.

The sensorless IM drive system has been tested with step change in the load torque from 10 N.m to 20 N.m. Figure 5 shows the drive response when the rotor resistance is increased by a $150 \%$ of its nominal value at command speed of $100 \mathrm{rad} / \mathrm{sec}$. This figure shows that, the actual and estimated speed has the same track and the d-axis rotor flux component is equal to its command value. Also, the q-axis rotor flux component is equal to zero that satisfies the vector control principles.

In a different manner, a ramp variation of the rotor resistance from its nominal value to $150 \%$ of its nominal value is assumed as shown in Fig. 6. This figure shows the results at speed of $150 \mathrm{rad} / \mathrm{sec}$. While, Figs. 7 show the performance of the sensorless IM drive at different rotor speed of $100 \mathrm{rad} / \mathrm{sec}$ respectively with the ramp variation of rotor resistance.

\section{(b) actual and estimated stator resistance (ohm)}

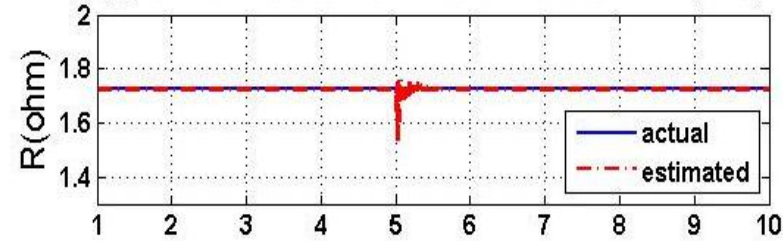

(d) speed error(estimated-actual)(rad/sec)

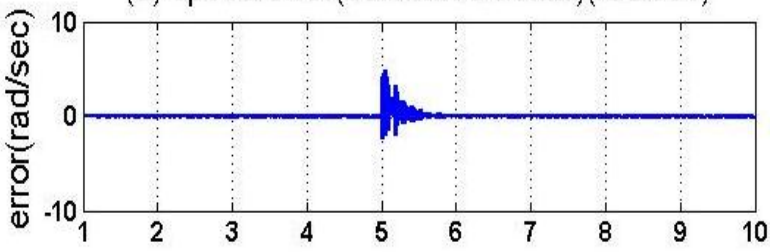

(f) $d-q$ rotor flux componant (web)

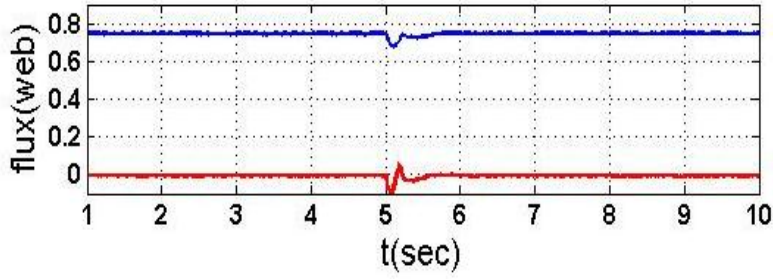

Figure 3: The effect of rotor resistance variation on the motor drive performance at very low speed. 


\section{Vol. 41, No.2. July 2022}

(a) actual and estimated rotor resistance (ohm)

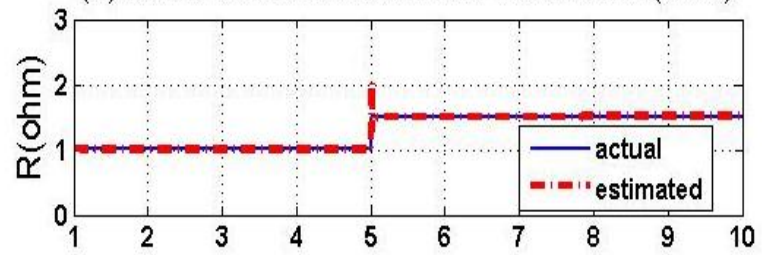

(c) actual and estimated speed ( $\mathrm{rad} / \mathrm{sec})$

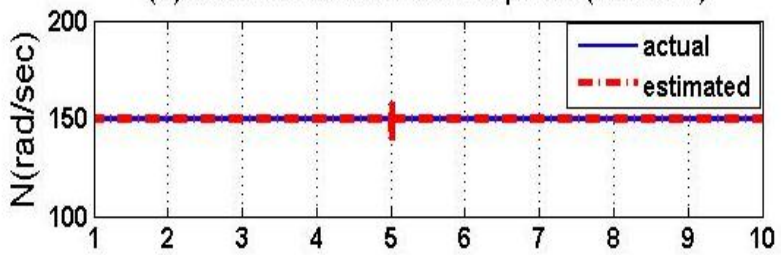

(e) electromagnetic and load torque $(\mathrm{Nm})$

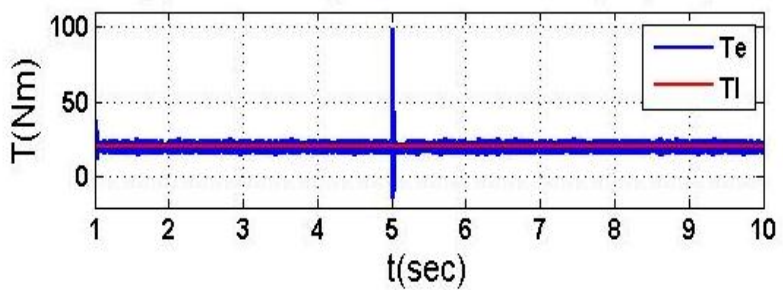

(b) actual and estimated stator resistance (ohm)

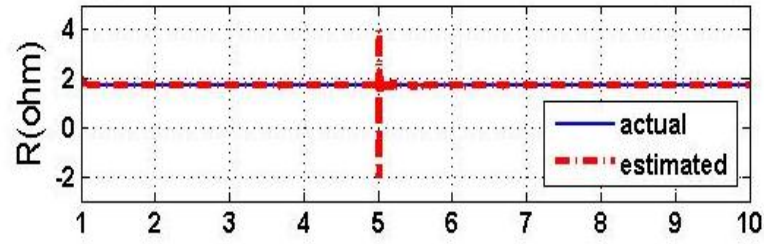

(d) speed error(estimated-actual)(rad/sec)

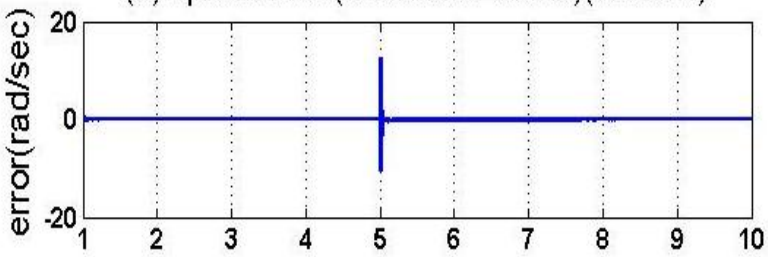

(f) d-q rotor flux componant (web)

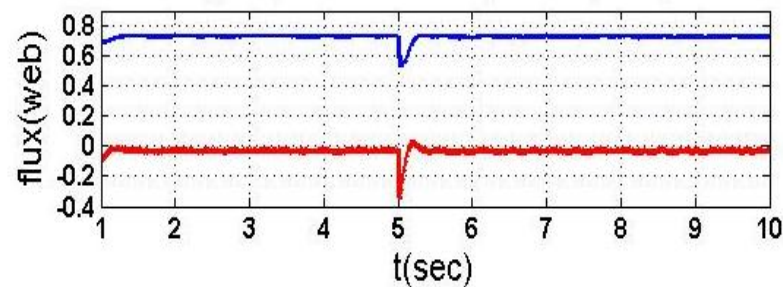

Figure 4: Estimation of rotor resistance and speed for induction motor drive performance at high speed $150 \mathrm{rad} / \mathrm{sec}$.

(a) actual and estimated rotor resistance (ohm)

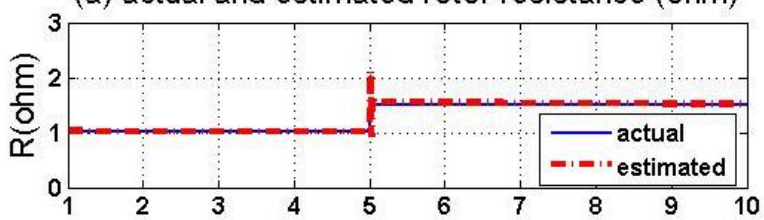

(c) actual and estimated speed (rad/sec)

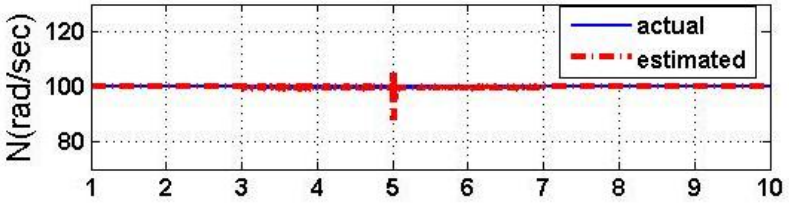

(e) electromagnetic and load torque $(\mathrm{Nm})$

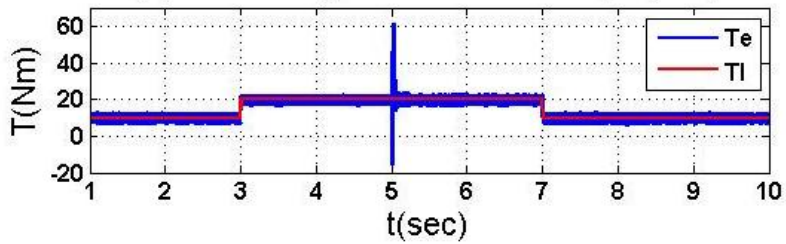

(b) actual and estimated stator resistance (ohm)

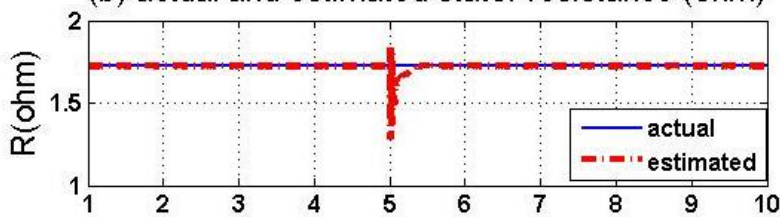

(d) speed error(estimated-actual)(rad/sec)

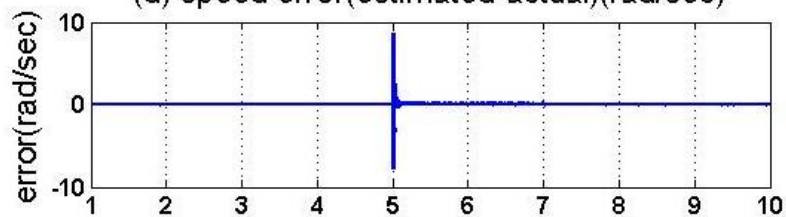

(f) d-q rotor flux componant (web)

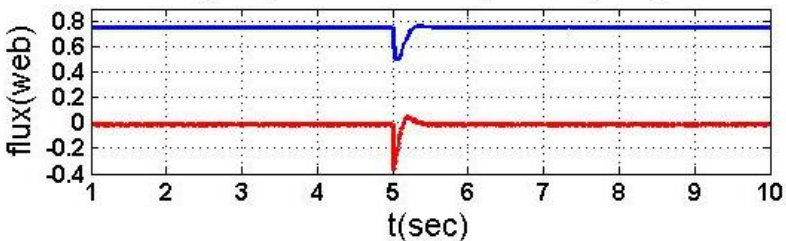

Figure 5: Performance of the proposed sensorless drive system for load torque disturbance at $100 \mathrm{rad} / \mathrm{sec}$. 
(a) actual and estimated rotor resistance (ohm)

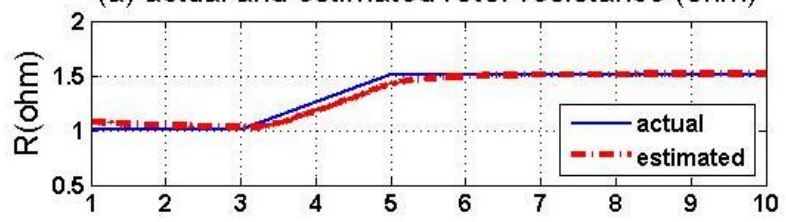

(c) actual and estimated speed (rad/sec)

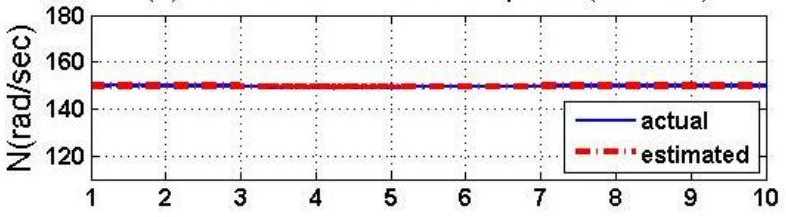

(e) electromagnetic and load torque ( $\mathrm{Nm})$

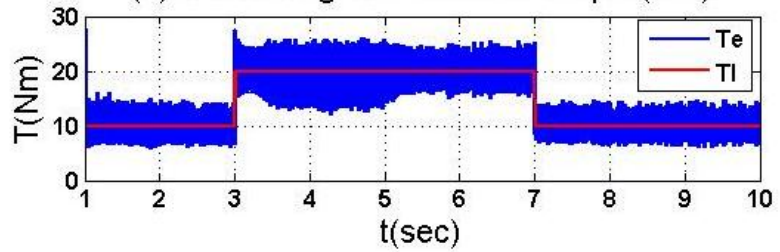

(b) actual and estimated stator resistance (ohm)

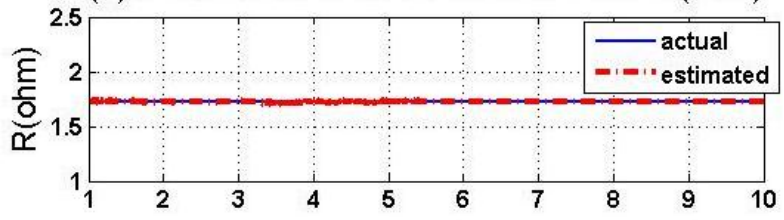

(d) speed error(estimated-actual)(rad/sec)

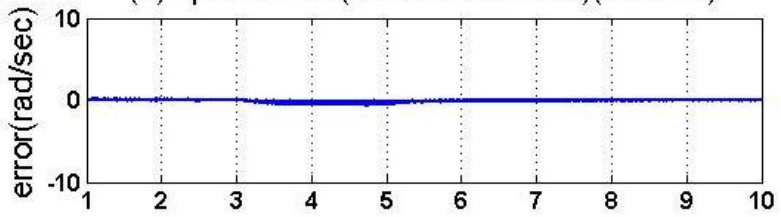

(f) $d-q$ rotor flux componant (web)

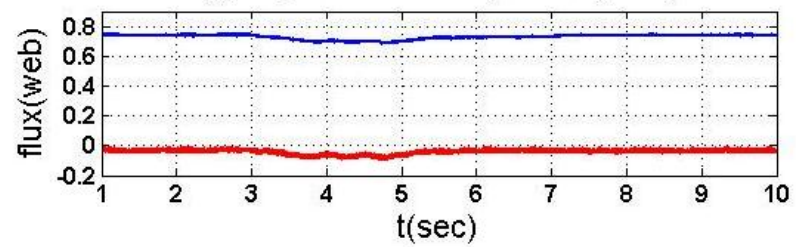

Figure 6: Performance of the proposed sensorless drive system for load torque disturbance at high speed of $150 \mathrm{rad} / \mathrm{sec}$.

(a) actual and estimated rotor resistance (ohm)

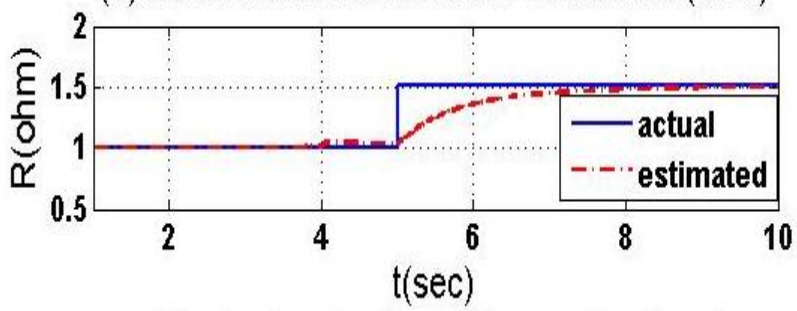

(c) actual and estimated speed (rad/sec)

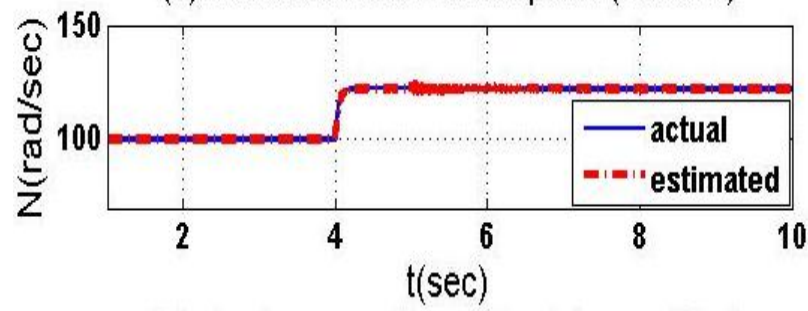

(e) electromagnetic and load torque (Nm)

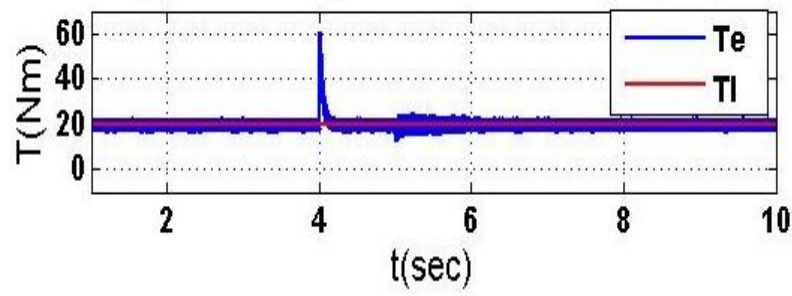

(b) actual and estimated stator resistance (ohm)

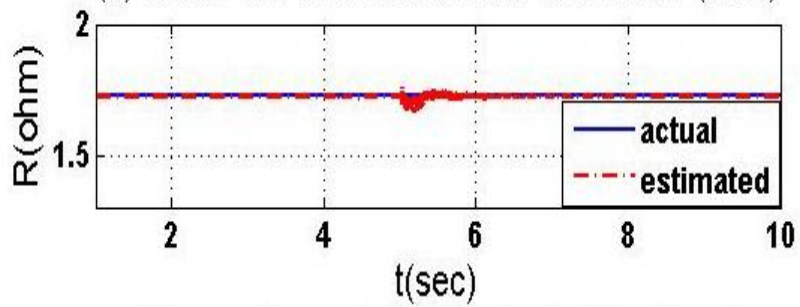

(d) speed error(estimated-actual)(rad/sec)

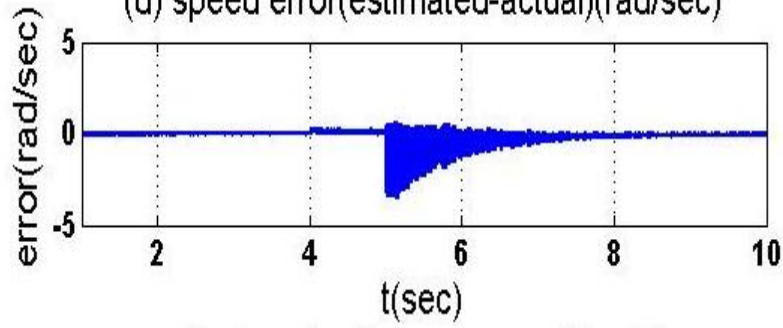

(f) d-q rotor flux componant (web)

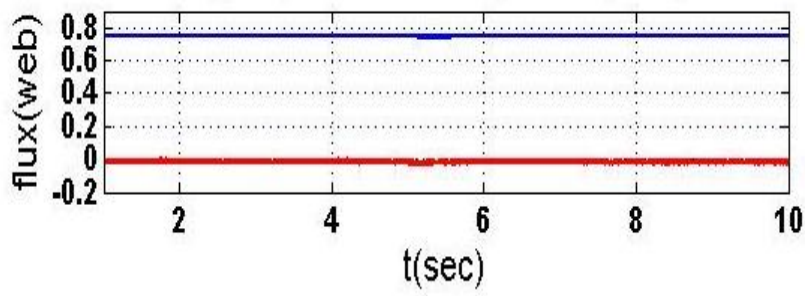

Figure 7: Performance of the proposed sensorless drive system with step increase in the rotor resistance $($ speed $=100 \mathrm{rad} / \mathrm{sec}$.) 
(a) actual and estimated rotor resistance (ohm)

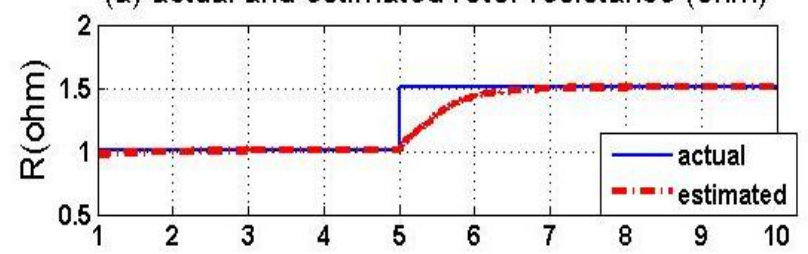

(c) actual and estimated speed ( $\mathrm{rad} / \mathrm{sec})$

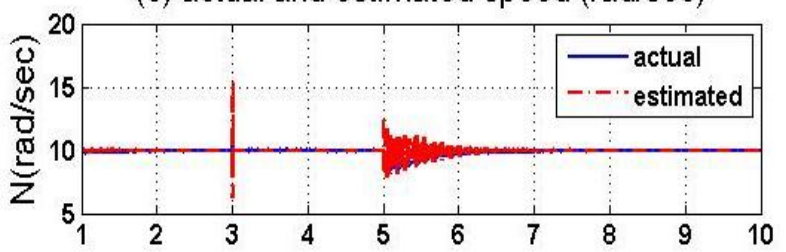

(e) electromagnetic and load torque (Nm)

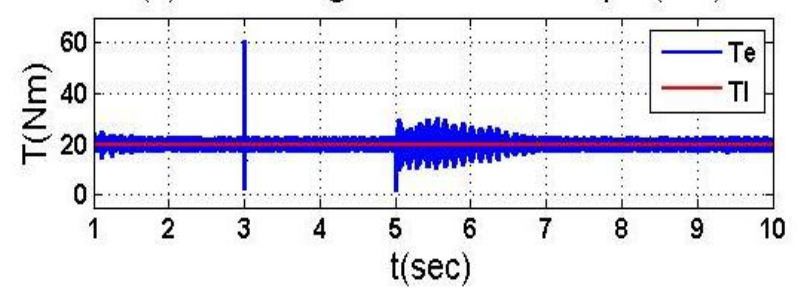

(b) actual and estimated stator resistance (ohm)

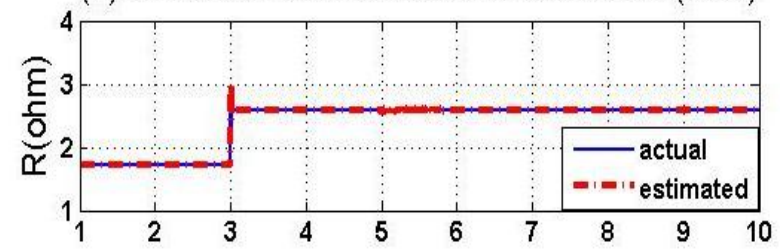

(d) speed error(estimated-actual)(rad/sec)

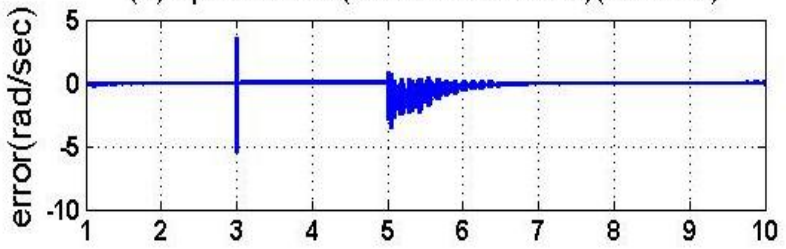

(f) d-q rotor flux componant (web)

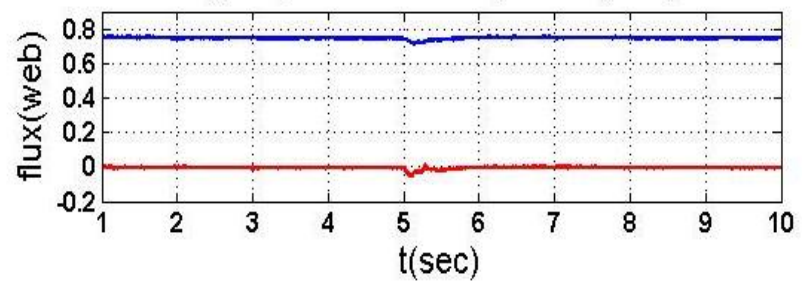

Figure 8: Motor performance with step increase in the stator and rotor resistance at very low speed.

(a) actual and estimated rotor resistance (ohm)

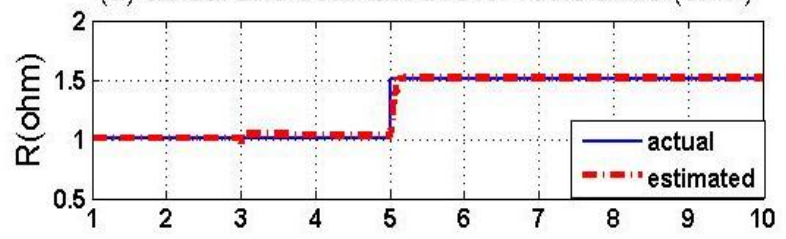

(c) actual and estimated speed (rad/sec)

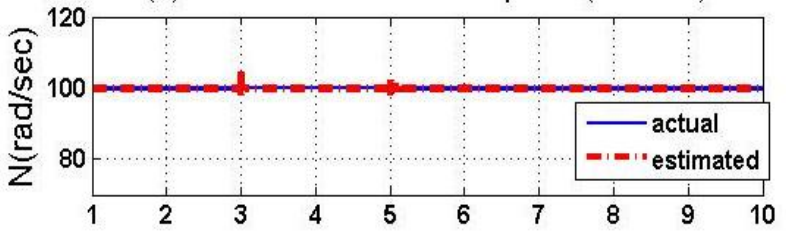

(e) electromagnetic and load torque (Nm)

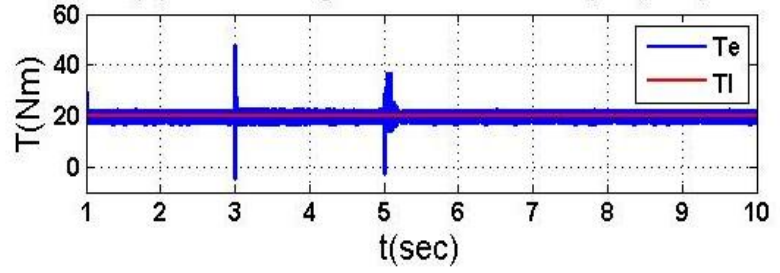

(b) actual and estimated stator resistance (ohm)

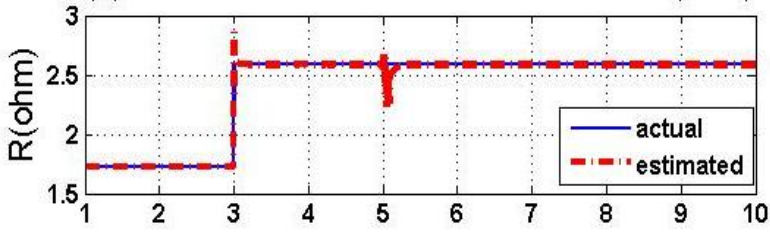

(d) speed error(estimated-actual)(rad/sec)

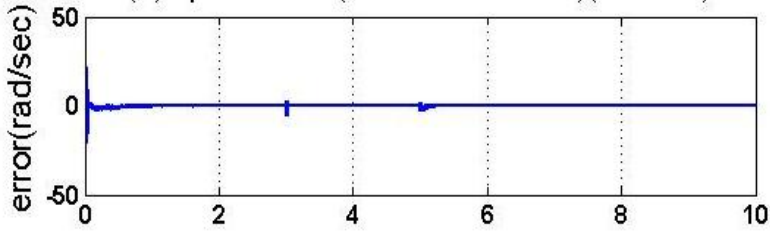

(f) d-q rotor flux componant (web)

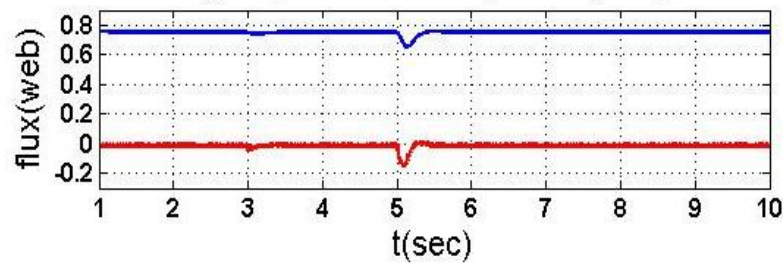

Figure 9: Motor performance with step increase in the stator and rotor resistance at low speed. 
(a) actual and estimated rotor resistance (ohm)

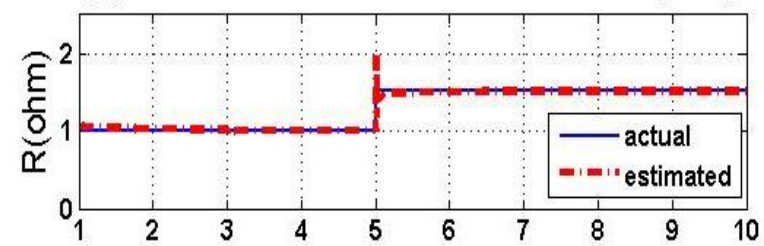

(c) actual and estimated speed (rad/sec)

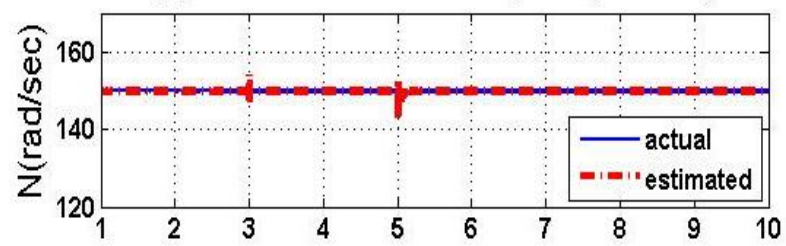

(e) electromagnetic and load torque ( $\mathrm{Nm})$

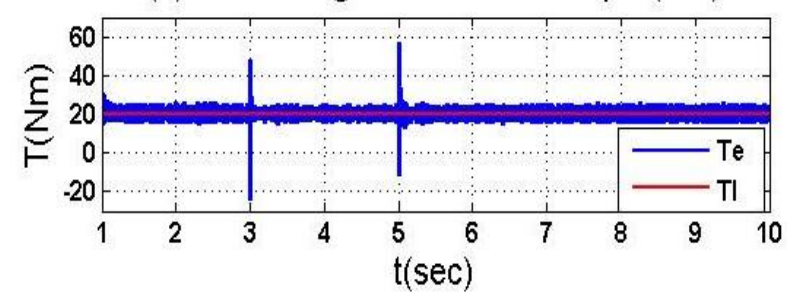

(b) actual and estimated stator resistance (ohm)

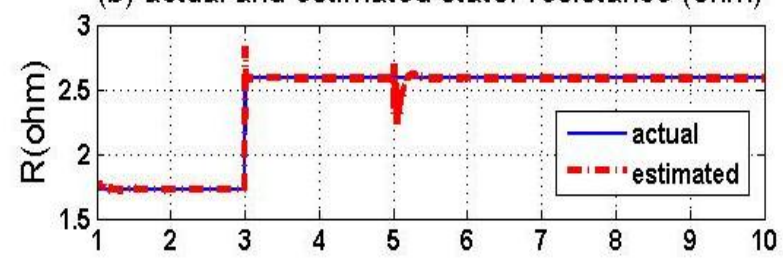

(d) speed error(estimated-actual)(rad/sec)

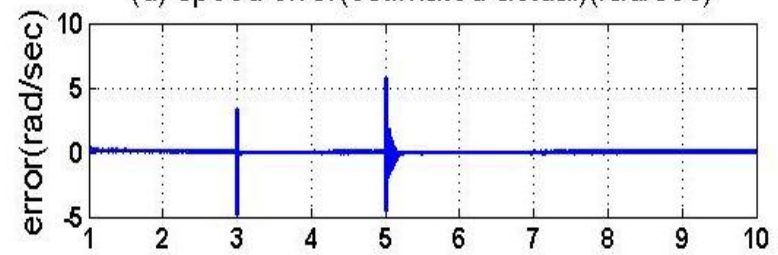

(f) d-q rotor flux componant (web)

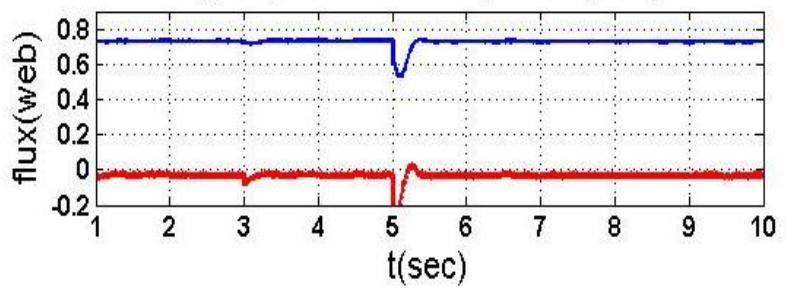

Figure 10: Motor performance with step increase in the stator and rotor resistance at high speed.

The variation in stator resistance will be done in parallel with the rotor resistance to ensure the stability of the drive system. Figures 8- 10 show the variation of stator and rotor resistance by a $150 \%$ of its nominal values. The motor speed in these cases is kept constant at $10 \mathrm{rad} / \mathrm{sec}, 100 \mathrm{rad} / \mathrm{sec}$ and $150 \mathrm{rad} / \mathrm{sec}$ respectively. From these figures, a good dynamic performance and an accurate estimation of rotor resistance and rotor speed have been achieved.

\section{Conclusions}

This paper presented a novel MRAS for estimation stator, rotor resistances and rotor speed for sensorless IM drive simultaneously. This algorithm achieves a highprecise control in a wide range of motor speed and saves the implementation cost and processes time. Moreover, the stability of the control scheme is derived using Popov's criterion to obtain the adaptation mechanisms. Simulation tests are performed for investigation the performance of presented scheme under different operating conditions. The simulation results show that, the dynamic performance of the presented drive is satisfactory at very low speed as well as high speed operation under the load torque disturbance.

\section{References}

[1] M. Zaky, et al., "Speed-sensorless control of induction motor drives (Review Paper)", ERJ,
Minoufiya Univ., Egypt, Vol. 30, No. 4, pp. 433444, October 2007.

[2] A. Consoli, G. Scarcella, and A.Testa, "SlipFrequency Detection for Indirect Field Oriented Control Drives", IEEE Trans. Ind. Appl., Vol. 40, No. 1, pp. 194-201, 2004.

[3] H. Toliyat, E.Levi, M. Raina, "A review of RFO induction motor parameter estimation techniques", IEEE Trans. on Energy Conversion, Vol. 18, No. 2, pp. 271-283, 2003.

[4] B. Karanayil, M.F. Rahman, and C. Grantham, "Rotor Resistance Identification using Artificial Neural Networks for an Indirect Vector Controlled Induction Motor Drive", Proc. of the $27^{\text {th }}$ Annu. Conf. of Industrial Electronics Society, IECON2001, Nov 29 - Dec 2, Denver, USA, Vol. 2, pp. 1315-1320, 2001.

[5] P. Roncero-Sa' nchez, et al., "Rotor-resistance estimation for induction machines with indirectfield orientation", Control Engineering Practice, 2007, Doi:10.1016/j.conengprac.2007.01.006.

[6] T. Matsuo, T. Lipo, “A rotor parameter identification sachem for vector controlled induction motor drives", IEEE Trans. on Ind. App., Vol. 21, pp. 624632, May/June 1985.

[7] R. Marino, S. Percsada, and P. Valigi, "Adaptive input-output linearizing control of induction motors", IEEE Trans. Automatic Control, Vo1. 38, pp. 208-221, Feb. 1993. 


\section{Vol. 41, No.2. July 2022}

[8] M. Barut, OS. Bogosyan, and M. Gokasan, "Switching EKF technique for rotor and stator resistance estimation in speed sensorless control of IMs", Energy Conversion and Management, Vol. 48, pp. 3120-3134, 2007.

[9] S. Wade, M. Dunnigan, and B. Williams, "Modeling and Simulation of Induction Machine Vector Control with Rotor Resistance Identification", IEEE Trans. on power electronics, Vol. 12, No. 3, pp. 495-50, May 1997.

[10] C. Schauder, "Adaptive speed identification for vector control of induction motors without rotational transducers", IEEE Trans. Ind. Appl., Vol. 28, No. 5, pp. 1054-1061, Sep. /Oct. 1992.

[11] S. Tamai, H. Sugimoto, and Y. Masao, "Speed sensorless vector control of IM with model reference adaptive system", in conf. Rec. IEEE/IAS Annu. Meeting, pp. 189-195, 1987.

[12] M. Rashed, and A. Stronach, "A stable back EMF MRAS based sensorless low speed induction motor drive insensitive to stator resistance variation", Inst. Electr. Eng. Proc. Electr. Power Appl., Vol. 151, No. 6, pp. 685-693, Nov. 2004.

[13] T. orlowska-kowalska, and M. Dybkowski, "StatorCurrent-Based MRAS Estimator for a Wide Range Speed-Sensorless IM drive", IEEE Trans. Ind. electronics, Vol. 57, No. 4, April 2010.

[14] A. Diab, "Real-Time Implementation of Full-Order Observer for Speed Sensorless Vector Control of
Induction Motor Drive", Springer, Journal of Control, Automation and Electrical Systems, Vol. 25, No. 6, pp. 639-648, December 2014.

[15] Diab, Ahmed A. Zaki, Abou-Hashema M. El-Sayed, Hossam Hefnawy Abbas, and Montaser Abd El Sattar. "Robust Speed Controller Design Using H_infinity Theory for High-Performance Sensorless Induction Motor Drives." Energies 12, no. 5 (2019): 961. https://doi.org/10.3390/en12050961

[16] Ahmed A. Zaki Diab, "Novel robust simultaneous estimation of stator and rotor resistances and rotor speed to improve induction motor efficiency", Int. J. of Power Electronics, 2017 Vol.8, No.4, pp.267 287 ,

2017. https://doi.org/10.1504/IJPELEC.2017.085197

[17] AAZ Diab, Robust simultaneous estimation of stator and rotor resistances and rotor speed for predictive maintenance of sensorless induction motor drives, Inderscience Publishers (IEL), International Journal of Power and Energy Conversion, Vol. 8, Issue 4, pp.

411-4342017. https://doi.org/10.1504/IJPEC.2017.087325

[18] Diab AAZ, Abdeen ME, Elwany MA, Hassaneen BM (2016) Rotor Resistance Estimation for Predictive Maintenance of Sensorless Induction Motor Drives. J Electr Eng Electron Technol 5:2. doi:10.4172/2325-9833.1000126., 2016.

ملخص- يهدف البحث إلى تقديم طريقة جديدة معتمداً على النموذج المرجعي للنظام الملائم (MRAS) المحرك On-line simultaneous Estimation

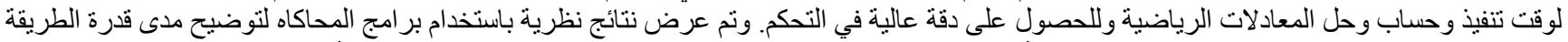

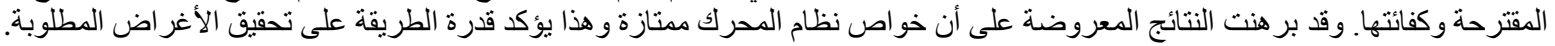

